\title{
METAFÍSICA DA MORTE
}

\author{
METAPHYSICS OF DEATH
}

Leonardo Oliveira

\begin{abstract}
RESUMO
O fenômeno da modernidade alterou o curso previamente seguido pela morte. Em séculos anteriores morria-se na familiaridade do próprio lar e o morrer adquiria caráter de espetáculo, que era acompanhado pela comunidade dos vivos. Após o século XX a morte tornou-se fria, distante e impessoal. A busca pelo sentido do ser, no entanto, permaneceu basicamente imutável; uma vez que o Dasein é um "ser/estar-para-a morte", faz-se inerente ao homem a elaboração de questionamentos ontológicos, que podem originar angústia e negação. No presente artigo busca-se compreender, de modo geral, a relação entre o Dasein heideggeriano e o fenômeno da morte, partindo-se da ideia de que tal associação se trata de uma realidade metafísica.
\end{abstract}

Palavras-chave: Morte; Angústia; Dasein.

\begin{abstract}
The phenomenon of modernity changed the course previously followed by death. In previous centuries, one used to die in the familiarity of one's own home and death had become a spectacle attended by the community of the living. After the twentieth century death became cold, distant and impersonal. The search for the sense of being, however, remained basically unchanged; since Dasein is a "being-toward-death", it is inherent to the human being the elaboration of ontological questions, which can rise angst and denial. The present article intends to understand, in a general way, the relation between the heideggerian's Dasein and the phenomenon of death, starting from the idea that such association is a metaphysical reality.

Keywords: Death; Angst; Dasein.
\end{abstract}

"Estamos longe de uma verdadeira metafísica

da morte e também da vida ${ }^{1 "}$.

\section{O Dasein como "estante-aí" para a morte}

Heidegger objetiva em Ser e Tempo (1927), a partir de movimento hermenêutico circular e do método fenomenológico de Husserl, compreender as vicissitudes do ser humano - ou Dasein, nas palavras do autor - sob prisma analítico e existencialista. Um dos argumentos heideggerianos centrais consiste em situar o tema da morte como caminho para a descoberta do sentido do ser: "Para Heidegger a morte pertence à própria estrutura essencial da existência. Ela não é um acidente, não vem de fora. A existência humana é um ser-para-a-morte (Seinzum-Tode) ${ }^{2 \prime \prime}$.

${ }^{1}$ LANDSBERG, 2009, p. 13.

${ }^{2}$ MARANHÃO [1985], 1998, p. 69.

${ }^{3}$ BORNHEIM, 2001, p. 177.

\begin{abstract}
A questão do ser atravessa de modo singular toda a obra de Heidegger. A pergunta é invariavelmente a mesma: o que é o ser? O que dizemos quando pronunciamos a palavra ser? E, no entanto, Heidegger não dá, propriamente falando, resposta à pergunta ${ }^{3}$.
\end{abstract}

Visto que o ser humano é hermenêutico por natureza, como sinaliza o próprio autor de Ser e Tempo, a pergunta fundamental e universal do Dasein resvalaria inevitavelmente na busca pelo sentido do ser, isto é, na compreensão da relação entre homem e cosmos. Conformaria, portanto, um questionamento ontológico.

Uma vez que a existência humana não consiste na mera presença no mundo, esta tampouco poderia ser analisada apenas do ponto de vista ôntico, ou seja, a partir de um estudo orientado em busca do sentido do ente, visto que uma análise ôntica demanda um questionamento ontológico prévio, como indica 
Heidegger: “O perguntar ontológico é, sem dúvida, mais originário do que o perguntar ôntico das ciências positivas ${ }^{4 \prime}$. Se o ser humano é tão somente um ser/estarpara-a-morte, caberia o questionamento de Solomon: "será a vida apenas o adiamento absurdo da morte?"

O esforço de Heidegger para conceber uma analítica existencial resguarda, no entanto, seus méritos; como aponta Bornheim, a partir de Ser e Tempo a própria ideia de sistema tornou-se suspeita, "como suspeito se fez também o racionalismo que constitui o seu pressuposto; o sistema, esclarece Heidegger, é expressão metafísica da vontade de poder e, portanto, do subjetivismo que caracteriza de modo especialmente intenso o pensamento moderno ${ }^{6 "}$.

A tradução do termo Dasein, instaurado por Kant em Crítica da Razão Pura (1781), consistiria em "ser/estar-aí-nomundo". Os seguidores de Heidegger, de modo geral, operam com o sentido de ser-aí; para este artigo, no entanto, partir-se-á da segunda acepção, uma vez que se tem a ideia de que o ser humano está-aí permanentemente disponível para a morte, sendo a morte a única possibilidade permanente do Dasein: "Como poder-ser o Dasein não pode superar a possibilidade da morte. A morte é a possibilidade da pura e simples impossibilidade-de-ser-'aí ${ }^{\prime \prime \prime}$.

Dentre as possibilidades do Dasein, somente a morte é capaz de tornar todas as outras impossíveis, a aniquilação de todas as possibilidades. No entanto, certificar a iminência do fenômeno é, de certo modo, trivial $e$ insuficiente. Segundo Heidegger,

O caráter do iminente não distingue por si só a morte. Ao contrário: essa interpretação ainda poderia sugerir a suposição de que a morte devesse ser entendida no sentido de um acontecimento iminentemente vindo-deencontro no interior do mundo ambiente. Iminente pode ser, por exemplo, uma trovoada, a reforma da casa, a chegada de um amigo (...) A morte iminente não tem um ser dessa espécie ${ }^{8}$.

O sentido em destacar a iminência da morte seria tão somente colocá-la como forma de incentivo ao ser humano, no sentido de que a consciência da morte é o que o impele a colocar-se constantemente na busca pela concretização de projetos pessoais. Portanto, uma vez que a morte pode ceifar o futuro de modo imprevisível, o indivíduo encontrase permanentemente como "estante-aí" para a morte.

O aniquilamento, o perecer, daria fim a todo esse planejamento e esse cuidado. A vida não teria perspectiva: não há urgência em prosseguir com o que, agora, consideramos importante, nem novos empreendimentos, nenhum eu futuro para cuidar, nenhum eu absolutamente? .
Conforme a analítica de Heidegger, cada indivíduo está disponível para morrer apenas a própria morte ${ }^{10}$. Uma vez que não se pode morrer a morte alheia, a morte configura um fenômeno pessoal e intransferível, como ratifica o próprio autor: "A morte é a propriedade maisprópria do Dasein. [...] A morte não 'pertence' só indiferentemente ao Dasein próprio, mas ela o interpela como singular ${ }^{111}$. A angústia, segundo Heidegger, também é inerente ao Dasein e pode emergir na consciência humana a partir da busca pelo sentido do ser.

O conceito de angústia difere do conceito de medo na medida em que, enquanto o medo é adquirido diante de algo determinado, que possui caráter de ameaça, a angústia pode emergir diante de objeto, em geral, indeterminado:

A angústia não "vê" também um determinado "aqui" e
"ali" a partir do qual o ameaçador se aproximaria. Que o
ameaçador não esteja em parte alguma caracteriza o
diante-de-quê da angústia. A angústia "não sabe" o que
é aquilo diante-de-que se angustia (...) O diante-de-quê da
angústia é o mundo como tal"12.

Com base em Ser e Tempo, Maranhão sugere que a angústia humana é proveniente do "nada" e que pode invadir o indivíduo a partir do ponderamento de questões existenciais ${ }^{13}$, como a busca pelo sentido do ser, conforme indica Heidegger: “O diante-de-quê da angústia (Angst) é completamente indeterminado ${ }^{14 " .}$ Kovács, por sua vez, interpreta que a angústia colocaria em evidência a possibilidade do Dasein de ser o autor de sua própria história, a partir da construção ou ausência de sentido: "A angústia faz patente no ser-aí, o ser relativamente ao mais peculiar poder ser, quer dizer, o ser livre para a liberdade de eleger-se e empunhar-se a si mesmo ${ }^{15 "}$.

Conquanto livre, o ser humano tende a escapar à angústia da morte ${ }^{16}$. Entretanto, se a possibilidade de morrer faz-se inerente ao Dasein, pode-se dizer que se trata de uma fuga improfícua, uma vez que a angústia seria também fato inexorável.

\footnotetext{
${ }^{4}$ Ser e tempo [1927], 2010, § 3, p. 57.

${ }^{5}$ O demônio do meio-dia: uma anatomia da depressão, 2002, p. 229.

${ }^{6}$ Metafísica e finitude, 2001, p. 178.

${ }^{7}$ HEIDEGGER [1927], 2010, § 50, p. 691.

${ }^{8}$ Ser e tempo [1927], 2010, § 50, p. 691.

${ }^{9}$ LUPER [2009], 2010, p. 13-4.

${ }^{10}$ MARANHÃO [1985], 1998, p. 70.

${ }^{11}$ HEIDEGGER [1927], 2010, § 53, p. 723.

${ }^{12}$ Ser e tempo [1927], 2010, § 40, p. 523.

${ }^{13}$ O que é morte [1985], 1998, p. 70.

${ }^{14}$ Ser e tempo [1927], 2010, § 40, p. 521,

${ }^{15}$ HEIDEGGER, 1927, apud KOVÁCS, 1992, p. 143.

${ }^{16}$ KOVÁCS, 1992, p. 143.
} 
Na abertura [...] da angústia, nos angustiamos pelo ser no mundo enquanto tal. Nos deparamos com a falta de sentido no mundo, que não nos pode mais sustentar. Assim, nos apropriamos de que só nós podemos nos dar esta sustentação, ou seja, ser o autor do sentido de minha existência ${ }^{17}$.

Além da angústia do "nada", inerente ao Dasein, há a angústia frente à iminência de uma morte próxima. Neste caso, é possível que ambas se agravem mutuamente, visto que o ser humano tende a não ponderar sobre questões relativas ao próprio morrer no decurso de sua existência. Tais perspectivas são, em geral, suprimidas. A angústia perante a iminência da própria morte será brevemente ilustrada a seguir através da narrativa de Tolstói - A morte de Ivan Ilitch (1886) - a fim de compreender-se em que medida o Dasein poderia se afirmar enquanto "estante-ai" para a morte.

A narrativa de Tolstói, citada por Heidegger em nota de rodapé ("L. N. Tolstói, no seu conto "A morte de Ivã Ilitch", descreveu o fenômeno do abalo e do desmoronamento desse "a-gente morre"18), ilustra a morte arquetípica do século $X X^{19}$, que consiste em relegar o moribundo e a morte ao esquecimento, conforme será explicado no próximo subcapítulo desta pesquisa.

Ivan Ilitch, um burocrata russo bem-sucedido de quarenta e cinco anos, levava vida ordinária ao lado da mulher fruto de casamento arranjado - e do filho de tenra idade. Ambicioso e obcecado com promoções, preocupava-se em se mostrar comme il faut perante a sociedade ${ }^{20}$.

Cometeu na faculdade algumas ações que, antes, pareciam-lhe grande ignomínia e que suscitaram nele asco por si mesmo, no momento em que a cometia; mas, percebendo ulteriormente que essas ações eram cometidas também pelas pessoas altamente colocadas e não eram consideradas por elas como ações más, não é que ele as tivesse considerado boas, mas esqueceu-as de todo e não se entristecia um pouco sequer ao lembrá-las ${ }^{21}$.

A ascensão na carreira trouxe a Ivan Ilitch novas possibilidades. A partir da proposta de assumir cargo ministerial em outra cidade, o burocrata adquire novo apartamento para si e sua família, caracterizando momento de grande júbilo na narrativa. Uma vez

\footnotetext{
${ }^{17}$ Ibidem, p. 145.

${ }^{18}$ Ser e tempo [1927], 2010, § 51, p. 699.

${ }^{19}$ KÓVACS, 1992, p. 38.

${ }^{20}$ ARIÈS [1977], 2014, p. 760-1.

${ }^{21}$ TOLSTÓI [1886], 2009, p. 19.

${ }^{22}$ Ibidem, p. 31

${ }^{23}$ Ibidem, p. 32

${ }^{24}$ ARIÈS [1977], 2014, p. 761-2.

${ }^{25}$ O homem diante da morte [1977], 2014, p. 763.

${ }^{26}$ TOLSTÓI, 1886, apud ARIÈS [1977], 2014, p. 762.

27TOLSTÓI [1886], 2009, p. 46-7.
}

instalados, Ivan Ilitch incumbe-se da tarefa de decorar a nova residência a seu gosto, entretanto, havia ali o mesmo que há em casa de todas as pessoas não muito ricas, mas que desejam parecê-lo e por isto apenas se parecem entre si: damascos, pau-preto, flores, tapetes e bronzes, matizes escuros e brilhantes; enfim, aquilo que todas as pessoas de determinado tipo fazem para se parecer com todas as pessoas de determinado tipo ${ }^{22}$.

Durante a incumbência, Ivan Ilitch escorrega e se lesiona, de modo que apenas um lado de seu corpo na região do rim - é contundido. O sobressalto, no entanto, não se faz motivo de preocupação, como indica o próprio personagem: “Não é à toa que pratico ginástica. Um outro estaria morto, mas eu só me machuquei um pouco aqui; quando se toca, dói, mas já está passando; só ficou uma simples esquimose ${ }^{23 "}$.

A partir de então se inicia o longo processo de agonia de Ivan Ilitch, permeado por angústia existencial semelhante ao conceito instaurado por Heidegger em Ser e Tempo: "começa a doença: mau hálito, dor de lado, nervosismo. Justifica uma consulta [...] A partir dessa primeira consulta, Ivan Ilitch agarra-se ao médico como um parasita ${ }^{24 "}$. Os médicos, no entanto, não são capazes de precisar o diagnóstico, engendrando no doente uma espécie de obsessão pela enfermidade obscura, como reafirma Ariès: "A doença aprisiona Ivan Ilich como um esquilo na sua gaiola25".

A angústia do personagem consiste também no fato de que a medicina não é capaz, todavia, de certificar a doença. Na tentativa de compreendê-la por si só, ele ingressa no ciclo médico de modo obstinado ao mesmo tempo em que tenta se convencer da própria convalescença e iminente cura.

\begin{abstract}
Desde a sua visita ao doutor... [sua] principal preocupação era de seguir estritamente as suas recomendações em relação à higiene e aos medicamentos, e observar atentamente sua dor [sintomas necessários ao diagnóstico]. Os interesses de Ivan Ilitch concentram-se nos doentes e na saúde ${ }^{26}$.
\end{abstract}

Ao ser confrontado pela possibilidade de ausência de cura, Ivan Ilitch depara-se pela primeira vez com o pensamento da própria morte. A iminência do fim traz à tona questionamentos ontológicos ao personagem, que não haviam sido feitos anteriormente em sua existência resumida ao ôntico e ao ordinário:

O caso não está no [...] rim, mas na vida e... na morte. Sim, a vida existiu, mas eis que está indo embora [...] e eu não posso detê-la. Sim. Para quê me enganar? [...] Existiu luz, e agora é a treva. Eu estive aqui, e agora vou para lá! Para onde? [...] Eu não existirei mais, o que existirá então, quando não existir mais? Será realmente a morte? ${ }^{27}$ 
Na medida em que o ser vige a partir da á $\lambda \hat{\theta} \theta \varepsilon ı$, pertence a ele o emergir autodesvelante. Nós denominamos isso a ação de auto-iluminar-se e a iluminação, a clareira [...]. Esses nomes se originam [...] de uma experiência do pensar primordial, para a qual a á $\lambda \hat{n} \theta \varepsilon\llcorner a$ necessita ser pensada de acordo com sua "verdade" própria, a ser percebida somente nela mesma ${ }^{33}$.

Indaga-se aqui, no entanto, se a verdade do ser não jazeria em sua "obscuridade"; neste caso, a busca pelo seu sentido seria possível somente a partir do ingresso no desconhecido do próprio Dasein: “Não faria nenhum sentido afirmar que o acesso ao ser se faz de modo transparente e total. [...] a luz do ser nunca é plena como a do sol, jamais apresenta o esplendor de algo que se oferece, ainda que por veredas difíceis, em sua plenitude $[\ldots]^{34}$. (FIGURA 1)

\section{A negação do Dasein}

\section{da própria morte}

Uma vez confrontado pela certeza da morte próxima - como foi o caso de Ivan Ilitch ao final da narrativa - desdobra-se o longo processo do morrer, onde os moribundos experimentam reações de reajustamento, isto é, os estágios de negação, cólera, barganha, depressão e aceitação, descritos por Kübler-Ross e interpretados por Maranhão. 0 autor destaca, no entanto, que "Nem todos passam pelos estágios dentro dessa ordem e [...] nem todos completam o processo 35 ".

Conforme Kübler-Ross, a negação está presente no discurso da maioria dos moribundos diagnosticados com doença terminal, mesmo que de modo parcial, seja no início da enfermidade ou em fases posteriores: “Esses pacientes podem considerar a possibilidade da própria morte durante um certo tempo, mas precisam deixar de lado tal pensamento para lutar pela vida". Sugere a autora que a negação, neste caso, operaria como uma espécie de "pára-choque" após a consciência da morte iminente, tanto embora configure mecanismo de defesa temporário ${ }^{36}$, como ilustra a postura de Ivan Ilitch perante sua doença não diagnosticada:

\footnotetext{
33Parmênides [2005], 2008, p. 155.

${ }^{34}$ Metafísica e Finitude, 2001, p. 180.

${ }^{35}$ O que é Morte [1985], 1998, p. 45.

${ }^{36}$ Sobre a Morte e o Morrer [1969], 2008, p. 44-5.

${ }^{37}$ TOLSTÓI [1886], 2009, p. 40-1.

${ }^{38}$ Morte e Desenvolvimento Humano, 1992, p. 41.

${ }^{39}$ KÜBLER-ROSS, 1969, apud MARANHÃO [1985], 1998, p. 43.

${ }^{40}$ O que é Morte [1985], 1998, p. 40-1.

${ }^{41}$ Tabu da Morte, 1983, p. 11-2.
}

A dor não diminuía; mas Ivan Ilitch esforçava-se, a fim de se obrigar a pensar que estava melhor. E ele conseguia enganar-se, enquanto nada o perturbava. [...] A sua piora desenvolvia com tamanha regularidade que ele podia enganar a si mesmo, fazendo uma comparação entre os dias consecutivos. [...] Será possível que eu me tenha enfraquecido tanto mentalmente? disse de si para consigo. - Bobagem! É tudo tolice, não devo entregar-me à hipocondria $[. . .]^{37}$.

A negação atuaria no sentido de deslocar a angústia trazida pela morte iminente para fora de si, tanto embora no caso de Ivan Ilich tal angústia tenha sido agravada pela postura omissa de seus familiares e do médico incumbido de sua doença. Chega-se, deste modo, ao que se pretende destacar aqui: o tratamento moderno dispensado ao moribundo durante seu morrer.

O recente progresso das ciências médicas no Ocidente possibilitou o prolongamento da expectativa de vida humana e, ao mesmo tempo, o distanciamento entre moribundos e a sociedade dos vivos. Segundo Kovács, o paciente terminal não possui status social ${ }^{38}$ e, segundo Kübler-Ross, não é visto como "pessoa ${ }^{39 "}$ ". Uma vez nesta condição e tendo-se em mente que pacientes terminais em geral são confiados ao espaço hospitalar, surge a probabilidade de que este seja isolado pela equipe médica responsável e, inclusive, pela própria família. Tal fenômeno, sugere Maranhão, pode ser sintoma de algo mais profundo: a tendência humana a escamotear a morte:

[Uma] "sociedade negadora da morte" como a nossa [...] está unicamente preocupada em qualificar pessoas aptas para curar, tratar e prolongar a vida, porém bem pouco aptas para assistir psicológica e humanamente pacientes que não vão se recuperar. [...] A dificuldade que [...] equipes de saúde experimentam no relacionamento com doentes próximos da morte deve-se [...] à sua incapacidade de lidar com os próprios temores da morte ${ }^{40}$.

\section{Conclusão}

- conhecimento trazido pela modernidade frequentemente impele o ser humano a racionalizar fenômenos de diversas origens. Entretanto, na tentativa de vislumbrar o fenômeno da morte sob perspectiva meramente científica, o homem encontra os limites de sua compreensão racional. Segundo Rodrigues, o intento de "cientificizar" o fenômeno da morte representa uma tentativa de fechar sua angústia em um discurso lógico e de encerrar o pensamento sobre a finitude em um lugar seguro dentro da sociedade e fora do indivíduo:

coerentemente, se em nossa sociedade os homens sempre se interessaram em estudar o que está distante (os "milagres" tecnológicos do futuro, os astros, os processos microfísicos, o mundo químico...), é compreensível que, no momento em que se quer banir a morte e afastá-la, ela se transforme em objeto de estudo científico ${ }^{41}$. 
Discursar cientificamente sobre a morte é atribuir-lhe o caráter de objeto e, logo, colocá-lo à distância e transformálo em ente passível de ser manipulado manualmente pelo homem, como um instrumento em laboratório ${ }^{42}$. Segundo Neves, Lopes e Moraes, "A atividade científica, desde seu surgimento no século XVI com Galileu, trata da produção de um saber sempre com um caráter parcial e provisório, nunca como uma verdade pretensamente última e absoluta ${ }^{43 "}$, portanto, o fenômeno da morte nunca poderá ser plenamente apreendido. Morin, por sua vez, metaforiza a finitude humana e questiona as intenções das ciências ao tentar compreendê-la:

La Rochefoucauld dizia que nem o sol nem a morte podem ser olhados de frente. De lá para cá, os astrônomos, com os artifícios infinitos de sua ciência de toda ciência - pesaram o sol, calcularam sua idade, anunciaram seu fim. Mas a ciência continuou como que intimidada e trêmula diante do outro sol, a morte ${ }^{44}$.

Diante desta afirmação, indaga-se a possibilidade e até mesmo a necessidade de racionalizar a morte humana. Se, em uma investigação científica, ao debruçar a mirada em apenas um aspecto do objeto perde-se o foco dos outros, não se pode investigar a morte senão de maneira limitada, pois "Ela não se deixa apreender, ela escapa ${ }^{45 " . ~ H a ́, ~ n o ~ e n t a n t o, ~ u m a ~ i n c o m p a t i b i l i d a d e ~}$ entre o caráter efêmero das coisas e o caráter permanente que a ciência insiste em atribuir a elas.

Medawar defende que o crescimento da ciência é autolimitado, isto é, diminui paulatinamente até atingir a estagnação, consequência do próprio processo de crescimento. Segundo o autor, não obstante a incapacidade da ciência para responder questões últimas, deve-se reconhecer que se trata de um "glorioso" empreendimento: "Censurar a ciência por sua incapacidade de responder todas as questões [...] é tão insensato quanto censurar uma locomotiva por não poder voar, ou por não poder realizar qualquer outra operação para a qual não foi projetada ${ }^{46 "}$.

Conclui-se por fim que investigações que objetivam compreender o fenômeno da morte serão sempre incompletas e limitadas, até porque tais tentativas frequentemente lidam não com a morte ou o morrer em si, mas com representações de morte engendradas pelo ser humano, o que as torna ainda mais abstratas e subjetivas.

\section{Referências bibliográficas}

ARIÈS, P. [1977]. O homem diante da morte. Trad. de Luiza Ribeiro. São Paulo: Editora Unesp, 2014. 837p.

BORNHEIM, G. A. [2001]. Metafísica e finitude. São Paulo: Editora Perspectiva, 2001. 231 p. (Coleção Debates; n. 280)

HEIDEGGER, M. [1927]. Ser e tempo. Trad. de Fausto Castilho. São Paulo: Editora da Unicamp; Rio de Janeiro: Vozes, 2012. 1200p. (Coleção Multilíngues de Filosofia Unicamp)

[2005]. Parmênides. Trad. de Sérgio Mário Wrublevski. Petrópolis: Vozes; Bragança Paulista: Editora Universitária São Francisco, 2008. 238p. (Coleção pensamento humano)

JUNG, C. G. et al. [1964]. O homem e seus símbolos. Trad. de Maria Lúcia Pinho. Rio de Janeiro: Nova Fronteira, 2002. 316p. (22 impressão)

KOTHE, F. R. [2016]. A poesia hermética de Paul Celan. Brasília: Editora Universidade de Brasília, 2016. 515p.

KOVÁCS, M. J. [1992]. Morte e desenvolvimento humano. $3^{a}$ ed. São Paulo: Casa do Psicólogo, 1992. 243p.

KÜBLER-ROSS, E. [1969]. Sobre a morte e o morrer. Trad. de Paulo Menezes. $9^{a}$ ed. São Paulo: Editora WMF Martins Fontes, 2008. 296 p.

LANDSBERG, P. L. [2009]. Ensaio sobre a experiência da morte e outros ensaios. Trad. de Estela dos Santos Abreu, Eliana Aguiar, César Benjamin e Antonio Mattoso. Rio de Janeiro: Contraponto: Ed. PUC-Rio, 2009. 219p.

LUPER, S. [2009]. A filosofia da morte. Trad. de Cecilia Bonamine. São Paulo: Editora Madras, 2010. 272 p.

MARANHÃO, J. L. de S. [1985]. O que é morte. $4^{\mathrm{a}}$ ed. São Paulo: Brasiliense, 1998. 77p. (Coleção primeiros passos, n. 150)

MEDAWAR, P. B. [1984]. Os limites da ciência. Trad. de Antonio Carlos Bandouk. São Paulo: Editora UNESP, 2008. $111 p$.

MORIN, E. [1921]. O homem e a morte. Trad. de Cleone Augusto Rodrigues. Rio de Janeiro: Imago, 1997. 356p. (Série Diversos)

\footnotetext{
${ }^{42}$ RODRIGUES, 1983, p. 11.

${ }^{43}$ Reintroduzindo o Sintoma: a Psicanálise como Obstáculo à Cientificização do Tratamento Psíquico, 2013, p. 238.

${ }^{44}$ O homem e a Morte [1921], 1997, p. 19.

${ }^{46}$ RODRIGUES, 1983, p. 12.

${ }^{47}$ Os Limites da Ciência [1984], 2008, p. 10-1.
} 
NEVES, T. I.; LOPES, A. M.; MORAES, T. C. B. [2013].

Reintroduzindo o sintoma: a psicanálise como obstáculo à cientificização do tratamento psíquico. Estudos e Pesquisas em Psicologia, Rio de Janeiro, v. 13, n. 1, 2013, pp. 237-253.

RODRIGUES, J. C. [1983]. Tabu da morte. Rio de Janeiro: Achiamé, 1983. 296 p.
SOLOMON, A. [2002]. O demônio do meio-dia: uma anatomia da depressão. Trad. de Myriam Campello. Rio de Janeiro: Editora Objetiva, 2002. 483 p.

TOLSTÓI, L. [1886]. A morte de Ivan Ilitch. Trad. de Boris Schnaiderman. $2^{\text {a }}$ ed. São Paulo: Editora 34, 2009. 96 p. (Coleção Leste) 
